\title{
Antioxidant treatment of experimental diabetic retinopathy in rats with nicanartine
}

\author{
H .P. H ammes ${ }^{1}$, A . B artmann ${ }^{2}$, L . E ngel ${ }^{2}$, P. Wülfroth ${ }^{2}$ \\ ${ }^{1}$ III Department of Internal Medicine, Justus-Liebig-University, Giessen, Germany \\ ${ }^{2}$ Department of Pharmacology, Merz and Co., Frankfurt, Germany
}

Summary In order to study the contribution of oxidant stress to the pathogenesis of experimental diabetic retinopathy, male streptozotocin diabetic Lewis rats were treated with the antioxidant and lipid-lowering compound nicanartine $(80 \mathrm{mg} / \mathrm{kg} ; \mathrm{n}=8$, blood glucose level $16.7 \pm 3.9 \mathrm{mmol} / \mathrm{l} ; \mathrm{HbA}_{1} 11.8 \pm 1.6 \%$ ) by oral supplementation for 6 months and compared with untreated diabetic $(n=6$; blood glucose $18.1 \pm$ $\left.1.4 \mathrm{mmol} / \mathrm{l} ; \mathrm{HbA}_{1} 11.5 \pm 1.5 \%\right)$ and untreated, nondiabetic rats $(n=8$; blood glucose $4.0 \pm 0.6 \mathrm{mmol} / \mathrm{l}$; $\mathrm{HbA}_{1} 4.8 \pm 0.9 \%$ ). Diabetic retinopathy was evaluated by computer-assisted quantitative morphometry including measurement of autofluorescent advanced glycated end-products and immunohistochemistry for heme oxygenase I. Antioxidant treatment did not inhibit the 3.1-fold increase of retinal advanced glycation end products, while the expression of heme oxygenase I in both vascular and glial structures was markedly reduced. Chronic hyperglycaemia led to a $37.3 \%$ increase in endothelial cells ( $p<0.001$ vs normal controls) and a $26.6 \%$ reduction in pericyte numbers ( $p<0.001$ vs controls). Both abnormalities were significantly ameliorated by nicanartine $(p<0.001 \mathrm{vs}$ diabetic controls). No effect was observed on the formation of acellular capillaries or microaneurysms. These data indicate that antioxidant therapy with nicanartine is of limited benefit in diabetic retinopathy, at least in the rodent model of streptozotocin-induced diabetes. [Diabetologia (1997) 40: 629-634]

Keywords Oxidant stress, nicanartine, diabetic retinopathy, rat, experimental.
Due to the results of the Diabetes Control and Complications Trial, it is now firmly established that chronic hyperglycaemia is the primary causal factor underlying the development of diabetic microangiopathy [1]. Several biochemical alterations are induced by elevated glucose levels all of which are possibly involved in the pathogenesis of diabetic retinopathy. For example, increased polyol pathway activity,

Received: 19 December 1996 and in revised form: 20 February 1997

Corresponding author: Dr. H.P. Hammes, III Department of Internal Medicine, Justus-Leibig University, Rodthohl 6, D35392 Giessen, Germany

A bbreviations: ROS, Reactive oxygen species; STZ, streptozotocin; TBARS, thiobarbituric reactive substances; PBS, phosphate buffered saline; HO-1, heme oxygenase-1; E/P ratio, erythrocyte/pericyte ratio. activation of protein kinase $\mathrm{C}$ due to de novo synthesis of diacylglycerol and glycation are among the main culprits [2-6].

There is also evidence to indicate that hyperglycaemia may induce diabetic angiopathy through the generation of oxidative stress. Reactive oxygen species (ROS) arise through metal-catalysed glucose autoxidation and by propagation through glycated proteins, yielding protein crosslinks and fluorescent products $[7,8]$. Glycoxidation products have been identified resulting from sequential glycation and oxidation reactions between reducing sugars and proteins $[9,10]$. Moreover, autoxidation of unsaturated lipids, present in plasma and cell membranes, is increased under hyperglycaemic conditions [11]. These lipid peroxidation products are toxic to microvascular cells suggesting a causal role in diabetic microvascular damage [12-14]. In vitro, the generation of these products can be abolished by chemical antioxidants [14]. 
The overall increase of oxidative stress in diabetes may not only result from increased generation of ROS, but also from compromised inhibitory and scavenging mechanisms. For example, endogenous antioxidant and scavenging protectors such as vitamin $\mathrm{E}$ and glutathione are depleted in diabetes and antioxidant enzymes such as superoxide dismutase and catalase are less active [15-18].

Based on these experimental observations, it has been postulated that diabetic retinopathy may be amenable to antioxidant treatment $[10,14]$. However, only preliminary experiments are available showing that probucol - a lipid lowering and antioxidant compound - ameliorates disturbed vascular permeability in the retinae of short-term diabetic rats [19].

Therefor, the aim of this study was to evaluate the effect of a new antioxidant compound, 2,6-Di-tert-butyl-4-[3-(3-pyridylmethoxy)propyl]phenol (nicanartine), on histological parameters of experimental retinopathy in the long-term streptozotocin (STZ)-diabetic rat. Nicanartine was primarily developed as an antiatherogenic drug, characterized by lipid-lowering, potent antioxidant and antiproliferative properties [20]. In non-diabetic rats, the compound lowers triglyceride levels more efficiently than probucol. It strongly inhibits cell- and $\mathrm{Cu}^{2+}$-induced lipid peroxidation of $\mathrm{LDL}$ with an $\mathrm{IC}_{50}$ of less than $5 \mu \mathrm{mol}$. HDL and VLDL fractions are also protected against lipid peroxidation. In vivo experiments in hypercholesterolaemic rabbits confirmed the in vitro data by showing that the susceptibility of lipoproteins to oxidative stress is greatly diminished. Nicanartine also inhibits smooth muscle cell proliferation after balloon catheter-induced endothelial injury and improves vascular reactivity as reflected by an increased response to acetylcholine-induced dilatation in cholesterol-fed and Watanabe rabbits [20-22].

\section{Materials and methods}

A nimals. The use of animals in this study conformed to the Association for Research in Vision and Ophthalmology Resolution on the Use of Animals in Research.

Six-week-old inbred Lewis rats weighing $202.8 \pm 11.7 \mathrm{~g}$ were used in the study (Zentralinstitut für Versuchstierkunde, Hannover, Germany). Chemical diabetes was induced by i.v. injection of streptozotocin $(65 \mathrm{mg} / \mathrm{kg}$ body weight; Boehringer Mannheim, Mannheim, Germany). After confirmation of stable hyperglycaemia (blood glucose level $>15 \mathrm{mmol} / \mathrm{l}$, 5 days after STZ injection), diabetic animals were randomly assigned to receive either standard rodent chow containing nicanartine $\left(80 \mathrm{mg} \cdot \mathrm{kg}\right.$ body weight ${ }^{-1} \cdot$ day $\left.^{-1} ; \mathrm{D}-\mathrm{N} ; \mathrm{n}=8\right)$ or no treatment $(\mathrm{DC} ; \mathrm{n}=6)$. Dosage of nicanartine was adjusted according to food consumption and body weight of the individual animals. According to in vivo studies in rats, nicanartine is readily absorbed after a single oral administration, with a peak plasma concentration of $1 \mathrm{mg} / \mathrm{l}$ after $1.5-2 \mathrm{~h}$ returning to baseline after $6 \mathrm{~h}$ [20]. Eight non-diabetic animals served as controls (NC).

All animals in the two diabetic groups received 1-2 IU of NPH insulin s.c. twice weekly to prevent critical weight loss (less than $180 \mathrm{~g}$ ) only during the first month after diabetes induction. Thereafter, insulin injections (1 IU) were given only occasionally, indicating stabilization of weight in both diabetic groups. No insulin was given during the last month of the experimental period.

Blood glucose, body weight and glycated haemoglobin (boronate affinity chromatography; Glyc Affin GHb, DRG, Marburg, Germany) were measured at regular intervals. Cholesterol and triglycerides were monitored at different time points. Blood was obtained at the end of the study to measure plasma concentrations of the drug and thiobarbituric acid reactive substances (TBARS) [23].

Retinal analysis. Retinae were obtained at the end of the study after enucleation of the eyes from the animals under deep anaesthesia and were immediately fixed in $4 \%$ buffered formalin.

Retinal vascular preparations were performed using a pepsin-trypsin digestion technique as previously described [24]. Briefly, a combined pepsin (5\% pepsin in $0.2 \%$ hydrochloric acid for $1.5 \mathrm{~h}$ ) trypsin $(2.5 \%$ in $0.2 \mathrm{~mol} / 1$ Tris for $15-30 \mathrm{~min}) \mathrm{di}$ gestion was used to isolate the retinal vasculature. Unstained preparations were used to measure autofluorescent advanced glycated end-products (AGE) by an established method [24, 25]. Although peroxidation products share with AGE the propensity of fluorescence, their excitation/emission wavelengths are different [26]. Subsequently, the samples were stained with periodic acid Schiff.

Acellular capillaries were quantitated using a grid of 100 fields, with which 10 microscopic fields covering a total area of $6.76 \mathrm{~mm}^{2}$ of retinal area were scored for the presence of acellular occluded vessels (integration ocular Olympus/ $400 \times$ magnification). Each field containing acellular capillary segments was recorded as positive, and values were normalized to $\mathrm{mm}^{2}$ of retinal area.

The total number of endothelial cells and pericytes was counted in ten randomly selected fields of the retina using an image analysing system (CUE 2; Olympus Opticals Inc., Hamburg, Germany). The numbers of both capillary cell types were normalized to the relative capillary density (numbers of cells per $\mathrm{mm}^{2}$ of capillary area). Retinae were completely evaluated for the total number of microaneurysms.

Immunohistology. Vertical cryostat sections of the contralateral eyes were scored for the expression of heme oxygenase I (HO-1; HSP 32) as an indicator of intracellular oxidative stress [27]. Briefly, tissue sections $(5-7 \mu \mathrm{m})$ were cut on a cryostat at $-20^{\circ} \mathrm{C}$ and placed on poly-lysine coated slides. After fixation with $96 \%$ (w/v) acetone for $5 \mathrm{~min}$, slides were air-dried, subsequently washed with $0.1 \mathrm{~mol} / \mathrm{l}$ phosphate-buffered saline (PBS) and blocked with PBS containing $3 \%(w / v)$ bovine serum albumin. A polyclonal anti-HO-1 antibody (raised against rat liver HO-1 (27); 1: 100; Stressgene, Dianova, Hamburg, Germany) was incubated with serial sections for $45 \mathrm{~min}$ at $22^{\circ} \mathrm{C}$. Slides were rinsed twice with PBS buffer and exposed to a fluoresciene isothiocyanate (FITC)-conjugated rabbit-anti-murine antibody (1:20; DAKO, Hamburg, Germany). Sections were rinsed again, coverslipped, and examined using an epifluorescence microscope (Olympus). Control slides were included by replacing the primary antibody with nonimmune murine $\mathrm{IgG}$.

\section{Statistical analysis}

All parameters are given as mean \pm SD. For statistical analysis, analysis of variance (ANOVA) and the Bonferroni multiple comparison test (Instat; GraphPad, San Diego, Calif., USA) were used. 
Table 1. Effect of streptozotocin-induced diabetes and nicanartine on metabolic parameters measured at the end of the study

\begin{tabular}{llll}
\hline & Controls & $\begin{array}{l}\text { Diabetic } \\
\text { controls }\end{array}$ & $\begin{array}{l}\text { Diabetic }+ \\
\text { nicanartine }\end{array}$ \\
\hline $\begin{array}{l}\text { Number } \\
\text { Body weight }(\mathrm{g})\end{array}$ & 8 & 6 & 8 \\
$\begin{array}{l}\text { Blood glucose } \\
(\mathrm{mmol} / \mathrm{l})\end{array}$ & $4.0 \pm 0.6$ & $18.1 \pm 1.4^{\mathrm{a}}$ & $16.7 \pm 3.9^{\mathrm{a}}$ \\
$\begin{array}{l}\text { HbA } 1 \%) \\
\begin{array}{l}\text { Total cholesterol } \\
(\text { mmol/l) }\end{array}\end{array}$ & $4.8 \pm 0.9$ & $11.5 \pm 1.5^{\mathrm{a}}$ & $11.8 \pm 1.6^{\mathrm{a}}$ \\
$\begin{array}{l}\text { Triglycerides } \\
(\mathrm{mmol} / \mathrm{l})\end{array}$ & $2.2 \pm 0.2$ & $2.1 \pm 0.2$ & $2.0 \pm 0.4$ \\
$\begin{array}{l}\text { TBARS } \\
(\% \text { of control) }\end{array}$ & $100 \pm 16.3$ & $106.1 .5 \pm 6.5$ & $111 \pm 14.4$ \\
\hline
\end{tabular}

Data are mean \pm SD

${ }^{\mathrm{a}} \mathrm{p}<0.05$ or less vs controls; ${ }^{\mathrm{b}} p<0.001$ vs diabetic controls

\section{Results}

Blood glucose, body weight, and glycated haemoglobin were comparable in untreated and treated diabetic animals and significantly different from non-diabetic controls (Table 1). The administration of nicanartine had no effect on overall glycaemia in diabetic rats. No change in total and HDL cholesterol levels of the treated diabetic group was observed. However, nicanartine reduced the threefold elevated level of triglycerides in untreated diabetic rats by $22 \%(p<0.001)$. Plasma TBARS were used as a marker of increased extracellular oxidative stress. Hyperglycaemia slightly increased plasma TBARS without reaching statistical significance. The levels remained unaffected by antioxidant treatment (Table 1).

Consistent with the pharmakokinetics of nicanartine, plasma levels were undetectable after a 12-h fasting period, as measured at the time the animals were killed.

The effect of the treatment was studied on the level of a retinal marker of intracellular oxidative stress, heme-oxygenase-1 (HO-1). While in DC (Fig. 1 b), a major increase of HO-1 immunoreactivity was observed both in vascular and non-vascular retinal tissue compared with non-diabetic controls (Fig. 1a); vascular immunolabelling was greatly reduced in nicanartine treated animals, indicating a specific effect of nicanartine on the vasculature in diabetes (Fig. 1c).

To test whether treatment with nicanartine would reduce the formation and accumulation of AGEs, we studied autofluorescent AGEs in retinal digests. No major difference in the amount of accumulated AGEs was discernible between treated and untreated diabetic groups (Table 2).

Chronic hyperglycaemia for 6 months in STZ-diabetic rats led to a $37.3 \%$ increase of retinal capillary endothelial cells (NC vs DC $p<0.001)$. Treatment
Table 2. Effect of nicanartine on retinal morphologic and morphometric parameters

\begin{tabular}{llll}
\hline & Controls & $\begin{array}{l}\text { Diabetic } \\
\text { controls }\end{array}$ & $\begin{array}{l}\text { Diabetic }+ \\
\text { nicanartine }\end{array}$ \\
\hline Numbers & 8 & 6 & 8 \\
Endothelial cells & $3270 \pm 340$ & $4490 \pm 580^{\mathrm{a}}$ & $4070 \pm 370^{\mathrm{a}, \mathrm{b}}$ \\
Pericytes & $2930 \pm 365$ & $2150 \pm 317^{\mathrm{a}}$ & $2470 \pm 270^{\mathrm{a}, \mathrm{b}}$ \\
$\begin{array}{l}\text { E/P ratio } \\
\begin{array}{l}\text { Acellular } \\
\text { capillaries }\end{array}\end{array}$ & $1.13 \pm 0.16$ & $2.14 \pm 0.37^{\mathrm{a}}$ & $1.66 \pm 0.22^{\mathrm{a}, \mathrm{b}}$ \\
$\begin{array}{l}\text { Microaneurysms } \\
\text { Retinal }\end{array}$ & 0 & $86.2 \pm 9.01^{\mathrm{a}}$ & $73.0 \pm 14.75^{\mathrm{a}}$ \\
$\begin{array}{l}\text { autofluorescent } \\
\text { AGEs (arbitrary units) }\end{array}$ & $42.0 \pm 7.89$ & $125.67 \pm 17.6^{\mathrm{a}}$ & $107.0 \pm 12.51^{\mathrm{a}}$ \\
\end{tabular}

Data are mean $\pm \mathrm{SD}$

${ }^{\mathrm{a}} \mathrm{p}<0.05$ or less vs controls; ${ }^{\mathrm{b}} \mathrm{p}<0.05$ or less vs diabetic controls

with nicanartine significantly reduced endothelial proliferation by $34.4 \%(p<0.001$ vs DC) (Table 2$)$.

Pericyte loss is the most characteristic and earliest morphological change in experimental diabetic retinopathy. In the diabetic group, a $26.6 \%$ reduction of pericyte numbers was observed. Nicanartine significantly diminished pericyte loss by $41.0 \%$, compared with DC $(p<0.001)$. The resultant $\mathrm{E} / \mathrm{P}$ ratio, which reflects total capillary cell composition independent of individual changes, was almost 1:1 $(1.13 \pm 0.16)$ in non-diabetic rats. Due to both endothelial proliferation and pericyte loss, the E/P ratio was significantly increased in the DC group $(2.14 \pm 0.37 ; \quad p<0.001$ vs NC). Treatment with nicanartine significantly ameliorated the $\mathrm{E} / \mathrm{P}$ ratio $(1.66 \pm 0.22 ; p<0.001$ vs DC).

Diabetic rats had a 3.1-fold increase in occluded capillaries (DC $86.2 \pm 9.01$ acellular capillaries $/ \mathrm{mm}^{2}$ of retinal area vs NC $27.4 \pm 14.0$ acellular capillaries/ $\mathrm{mm}^{2}$ of retinal area). In comparison with untreated diabetic rats, in diabetic animals treated with nicanartine there was no difference in their numbers of acellular capillaries (D-N 73.0 \pm 14.75 ) (Table 2).

The same finding applied to the occurrence of microaneurysms. While no microaneurysms were observed in non-diabetic groups, a small but equal number of microaneurysms was present in both diabetic groups.

\section{Discussion}

The assumption that antioxidants may prevent retinopathy in diabetes was based on studies showing increased generation of ROS under hyperglycaemic conditions and the toxicity of these products for microvascular cells in vitro $[7,10,14]$. However, our study demonstrates that antioxidant treatment has only a limited beneficial effect on diabetes-induced 


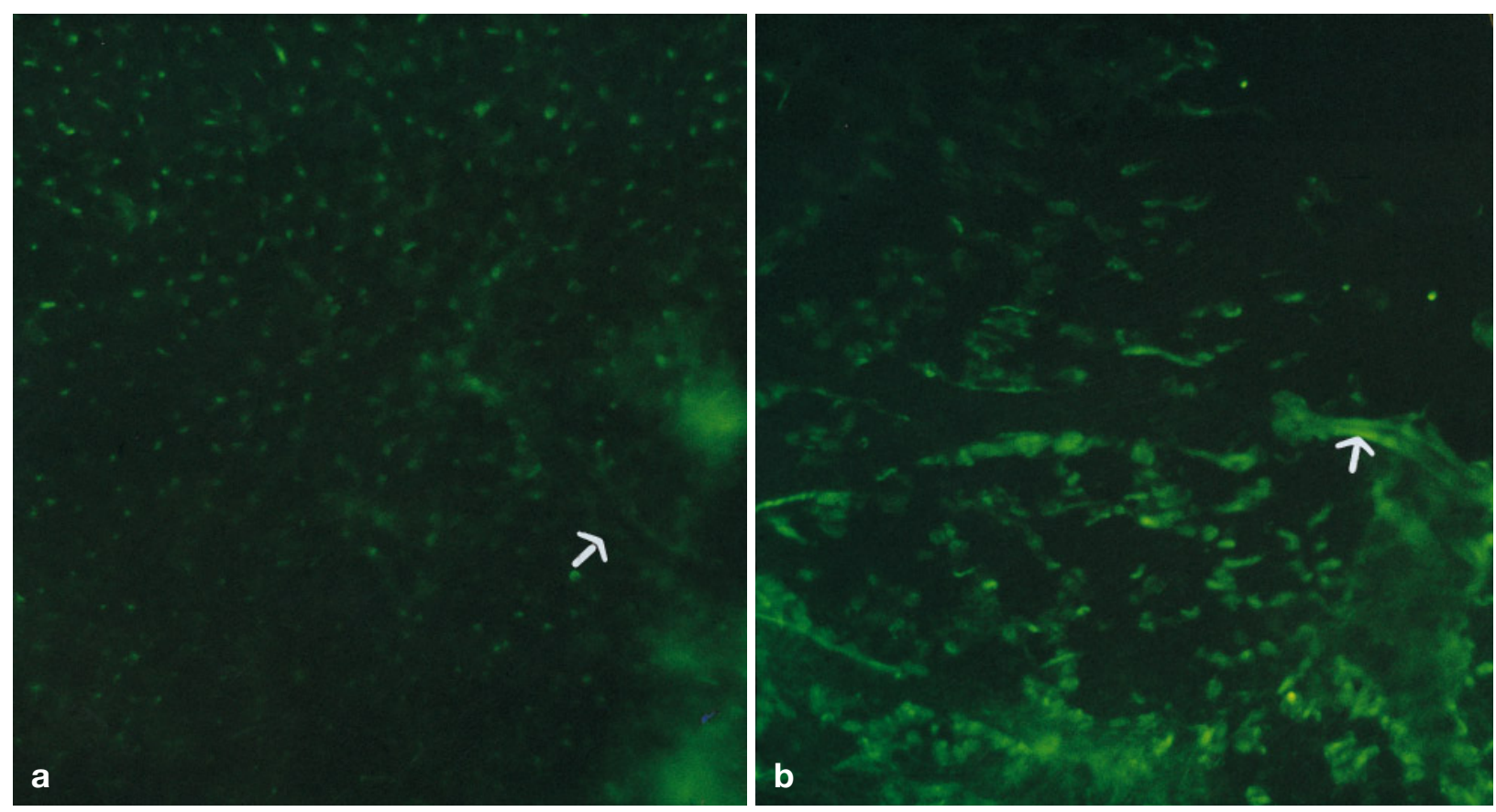

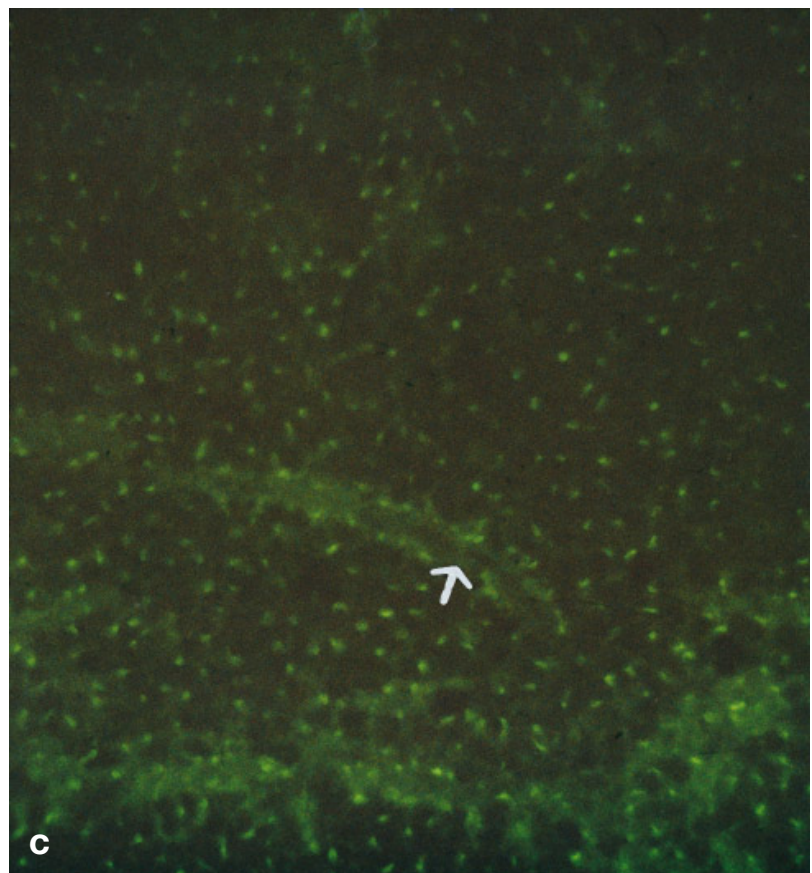

Fig. 1 a-c. Effect of nicanartine on the expression of heme oxygenase 1. Microphotographs show representative horizontal sections through the inner nuclear layer parallel to the inner limiting membrane, composed of neuroglial and vascular structures. (a) non-diabetic, (b) untreated diabetic, (c) diabetic, treated with nicanartine. Note the increased expression of heme oxygenase- 1 both in vascular (white arrow) and nonvascular structures of untreated diabetic rats (Fig.1b). Original magnification $400 \times$

microvascular changes in experimental diabetic retinopathy.

The antioxidant potency of nicanartine on in vitro lipid peroxidation has been reported to be higher than vitamin $\mathrm{E}$, especially in the VLDL fraction, and nicanartine inhibits endothelial-induced LDL oxidation more effectively than probucol, as measured by TBARS [20]. These data indicate that, in general, nicanartine is a potent antioxidant compound.

The efficacy of an antioxidant compound may vary in vivo due to its local bioactivity. There is biochemical as well as histological evidence that the dosage of nicanartine which was derived from previous experiments in rats was effective [20]. Hyperglycaemia-induced increased trigyceride levels were significantly lowered by nicanartine, indicating a biochemical effect of the compound. Diabetes induced an increased expression of retinal HO-1, a substitute marker for retinal intracellular oxidant stress in our model and this cellular response to increased oxidative stress was reduced by nicanartine. Heme oxygenase I (EC 1.14.99.3) is a regulatory enzyme in the heme degradative pathway that catalyses the oxidation of heme into biliverdin and $\mathrm{CO}$ [27]. A variety of processes can cause increased intracellular production of ROS in the retina, which uniformly lead to an upregulation of HO-1 as an indicator of increased intracellular oxidant stress [28-30]. As one example, retinal oxidant stress with HO-1 expression is induced in rats by exposure to intense visible light and is suppressed by antioxidant treatment [31]. Evidently, chronic hyperglycaemia induces similar cellular responses in the diabetic retina, but the cause for the moderate inhibitory effect of nicanartine on experimental retinopathy remains obscure. Consistent with our findings is the recent report by Kowluru et al. [32], showing that 2 months of antioxidant supplementation with $1 \%$ ascorbic acid and 0.1 
$\alpha$-tocopherol acetate lowered retinal TBARS as another measure of retinal oxidant stress.

The failure to detect an increase of TBARS in the plasma of the untreated diabetic rats is not unprecedented and can be explained by the insufficient specificity of this assay [33-35]. Among other reasons for this observation, it is possible that extracellular peroxidation products as measured by TBARS in diabetic rats are only transiently elevated [36]. Thus, data from our study together with reported findings suggest that the major permanent site of oxidant stress is intracellular.

In addition to its generation from glucose autoxidation and propagation through glycated proteins, another origin of intracellular oxidant stress in diabetic tissues is the interaction of specific cellular receptors with AGE in the matrix [28]. The activation of NF-kappaB, a pleiotrophic transcription factor, and of HO-1 have been observed, associated with cellular dysfunction and damage.

Therefore, the success of any antioxidant treatment may predominantly depend upon the ability of any compound to interfere with intracellular ROS formation.

Very recently, experiments using supplementation of $1 \%$ ascorbic acid and $0.1 \%$ alpha-tocopherol as antioxidant treatment were reported. Diabetic rats treated for 18 months with high doses of antioxidant vitamins showed only a modest effect on diabetic retinopathy. The formation of acellular capillaries was only moderately inhibited, while no effect was found on pericyte loss [37].

Although the results of that study contrast with data from our study with respect to the parameters affected by antioxidant treatment, they favour an alternative conclusion, which is that oxidative stress may not be a major cause of diabetic retinopathy. However, as with the study presented here, it may still be that antioxidants available so far are too weak to compensate for the retinal injury caused by hyperglycaemia-induced intracellular oxidant stress. Supporting such conclusions, experimental studies in diabetic rats revealed an acceleration of retinopathy as measured by a $75 \%$ increase of acellular occluded capillaries as the result of oral fish oil supplementation over a 6-month period [38].

Experimental evidence also suggests that the relative contribution of oxidative products accessible for antioxidant treatments is tissue-specific. While Soulis-Liparota et al. [33] were unable to detect any significant effect of probucol on albuminuria in STZ-diabetic rats over 32 weeks, Cameron et al. [39] reported a significant effect of probucol on nerve conduction velocity and nerve blood flow as early as after 1 and 2 months of diabetes, even in the presence of the pro-oxidant compound primaquine. Studies in experimental diabetic retinopathy using $1 \%$ probucol supplementation to the rat chow yielded comparable results to those of the present study with nicanartine [40].

Results from this study should not be extrapolated to human diabetes without caution, especially due to the more severe diabetic state of the animals studied and to the differences in lipid metabolism between rodents and humans [41, 42]. With the development of stronger antioxidant compounds which preferably should be targeted to interfere with increased intracellular oxidative stress, we anticipate that the true role of oxidation in the pathogenesis of diabetic retinopathy is assessable. Moreover, a subset of diabetic patients may exist in which the relative contribution of oxidative damage to the development of complications is mainly due to factors such as inherited impairment of defence systems or environmental/nutritional factors. In these cases, treatment using available antioxidants may deserve further consideration.

A cknowledgements. The excellent technical assistance of Ms. A. Weiss and Ms. B. Wellensiek is greatly appreciated. This study was partly supported by grant Ha 1755/1-3 from the German Research Council, Bonn, Germany.

\section{References}

1. DCCT Research Group (1993) The effect of intensive treatment of diabetes on the development and progression of long-term complications in insulin-dependent diabetes mellitus. N Engl J Med 329: 977-986

2. Kador PF, Robison WG, Kinoshita JH (1985) The pharmacology of aldose reductase inhibitors. Ann Rev Pharmacol and Toxicol 25: 691-714

3. Ruderman NN, Williamson JR, Brownlee M (1992) Glucose and diabetic vascular disease. FASEB J 6: 2905-2914

4. Greene DA, Lattimer SA, Sima AAF (1987) Sorbitol, phosphoinositide and the sodium-potassium ATPase in the pathogenesis of diabetic complications. New Engl J Med 316: 599-606

5. Lee TS, Saltsman KA, Ohashi K, King GL (1989) Activation of protein kinase $C$ by elevation of glucose concentration. Proposal for a mechanism in the development of diabetic vascular complications. Proc Natl Acad Sci USA 86: 5141-5145

6. Brownlee M (1994) Lilly lecture 1993. Glycation and diabetic complications. Diabetes 43: 836-841

7. Wolff SP, Dean RT (1987) Glucose autoxidation and protein modification. The potential role of "autoxidative glycosylation" in diabetes. Biochem J 245: 243-250

8. Mullarkey CJ, Edelstein D, Brownlee M (1990) Free radical generation by early glycation products: a mechanism for accelerated atherogenesis in diabetes. Biochem Biophys Res Commun 173: 932-939

9. Dyer DG, Blackledge JA, Katz BM et al. (1990) The Maillard reaction in vivo. J Nutr Sci 29: 13-20

10. Baynes JW (1991) Perspectives in diabetes. Role of oxidative stress in development of complications in diabetes. Diabetes 40: 405-412

11. Hicks M, Delbridge L, Yue DK, Reeve TS (1988) Catalysis of lipid peroxidation by glucose and glycosylated collagen. Biochem Biophys Res Commun 151: 649-655 
12. Morel DW, Hessler JW, Chisolm GM (1983) Low density lipoprotein cytotoxicity induced by free radical peroxidation of lipid. J Lipid Res 24: 1070-1076

13. Hessler JR, Robertson Jr AL, Chisolm III GM (1979) LDL-induced cytotoxicity and its inhibition by HDL in human vascular smooth muscle and endothelial cells in culture. Atherosclerosis 32: 213-229

14. Lyons TJ, Li W, Wells-Knecht MC, Jokl R (1994) Toxicity of mildly modified low-density lipoproteins to cultured retinal capillary endothelial cells and pericytes. Diabetes 43: 1090-1095

15. Watanabe J, Umeda F, Wakasugi H, Ibayashi H (1984) Effect of vitamin $\mathrm{E}$ on platelet aggregation in diabetes mellitus. Thromb Haemostas 51: 313-316

16. Uzel N, Sivas A, Uysal M, Oz H (1987) Erythrocyte lipid peroxidation and glutathione peroxidase activities in patients with diabetes mellitus. Horm Met Res 19: 8990

17. Crouch R, Kimsey G, Priest DG, Sarda A, Buse MG (1978) Effect of streptozotocin on erythrocyte and retinal superoxide dismutase. Diabetologia 15: 53-57

18. Jiang YZ, Towler HMA, Luthert P, Lightman S (1996) Pathophysiology of diabetic retinopathy. In: LeRoith D, Taylor SI, Olefsky JM (eds) Diabetes mellitus. LippincottRaven, Philadelphia pp. 719-727

19. Tilton RG, Chang K, Faller AF (1993) Probucol prevents vascular protein leakage induced by diabetes, glucose, and glycated proteins. Diabetes 42 [Suppl 1]:89A (Abstract)

20. Wülfroth PM (1995) Nicanartine. Drug of the Future. 20: 572-574

21. Wülfroth PM, Bartmann A, Hopstock CC, Reichel JE (1995) The new antioxidant MRZ 3/124 improves lipid status and prevents oxidative injury to endothelial cells and macrophages. Bull Mol Biol Med 20: 83-85

22. Wülfroth PM, Bartmann A, Hopstock C, Reichel J, Urien S, Tillement JP (1995) The new antioxidant MRZ 3/124 has a high affinity to lipoproteins and cells of the vascular wall thereby protecting against damage induced by reactive oxygen species. In: Jaross W et al. (eds) 1995 Advances in lipoproteins and atherosclerosis research, diagnostic and treatment. Jena, Stuttgart, New York, pp. 258-261

23. Esterbauer H, Striegl G, Puhl H, Rotheneder M (1989) Continuous monitoring of in vitro oxidation of human low density lipoprotein. Free Rad Res Comm 6: 67-75

24. Hammes HP, Martin S, Federlin K, Geisen K, Brownlee M (1991) Aminoguanidine treatment inhibits the development of experimental diabetic retinopathy. Proc Natl Acad Sci USA 88: 11555-11558

25. Monnier VM, Kohn RR, Cerami A (1984) Accelerated age-related browning of human collagen in diabetes mellitus. Proc Natl Acad Sci USA 81: 583-587

26. Odetti P, Pronzato MA, Noberasco G et al. (1994) Relationship between glycation and oxidation related fluorescences in rat collagen during aging. An in vivo and in vitro study. Lab Invest 70: 61-67

27. Maines MD, Trakshel GM, Kutty RK (1986) Characterization of two constitutive forms of rat liver heme oxygenase; only one form is induced. J Biol Chem 261: 411-419
28. Yan SD, Schmidt AM, Anderson GM et al. (1994) Enhanced cellular oxidant stress by the interaction of advanced glycation end products with their receptors/binding proteins. J Biol Chem 269: 9889-9897

29. Stocker R (1990) Induction of haem oxygenase as a defence against oxidative stress. Free Radical Res Commun 9: $101-112$

30. Schwartzman ML, Masferrer J, Dunn MW, McGiff JC, Abraham NG (1987) Cytochrome P450, drug metabolizing enzymes and arachidonic acid metabolism in bovine ocular tissues. Curr Eye Res 6: 623-630

31. Kutty RK, Kutty G, Wiggert B, Chader GJ, Darrow RM, Organisciak DT (1995) Induction of heme oxygenase 1 in the retina by intense visible light: suppression by the antioxidant dimethylthiourea. Proc Natl Acad Sci 92: 11771181

32. Kowluru RA, Kern TS, Engerman RL, Armstrong D (1996) Abnormalities of retinal metabolism in diabetes or experimental galactosemia. Effects of antioxidants. Diabetes 45: 1233-1237

33. Soulis-Liparota T, Cooper ME, Dunlop M, Jerums G (1995) The relative roles of advanced glycation, oxidation and aldose reductase inhibition in the development of experimental diabetic nephropathy in the Sprague-Dawley rat. Diabetologia 38: 387-394

34. Parinandi NI, Thompson EW, Schmid HH (1990) Diabetic heart and kidney exhibit increased resistance to lipid peroxidation. Biochim Biophys Acta 1047: 63-69

35. Oster MH, Llobet JM, Domingo JL, German JB, Keen C (1993) Vanadium treatment of diabetic Sprague-Dawley rats results in tissue vanadium accumulation and pro-oxidant effects. Toxicology 83: 115-130

36. Armstrong D, al Awadi F (1991) Lipid peroxidation and retinopathy in streptozotocin-induced diabetes. Free Radic Biol Med 11: 433-436

37. Kern TS, Kowluru RA, Engerman R (1996) Effects of antioxidants on the development of retinopathy in diabetes and galactosemia. Invest Ophthalmol Vis Sci 37/3:S970

38. Hammes HP, Weiss A, Führer D, Krämer HJ, Papavassilis C, Grimminger F (1996) Acceleration of experimental diabetic retinopathy by omega-3 fatty acids. Diabetologia 39: 251-255

39. Cameron NE, Cotter MA, Archibald V, Dines KC, Maxfield EK (1994) Anti-oxidant and pro-oxidant effects on nerve conduction velocity, endoneural blood flow and oxygen tension in non-diabetic and streptozotocin-diabetic rats. Diabetologia 37: 449-459

40. Hammes HP, Walter B, Weiss A, Federlin K (1996) Oxidativer Stress bei diabetischer Retinopathie: eine experimentelle Untersuchung. Diabetes \& Stoffwechsel 5: 136A

41. Mamo JC, Elsegood CL, Umeda Y, Hirano T, Redgrave TG (1993) Effect of probucol on plasma clearance and organ uptake of chylomicrons and VLDLs in normal and diabetic rats. Arterioscler Thromb 13: 231-239

42. Babiy AV, Gebicki JM, Sullivan DR, Willey K (1992) Increased oxidizability of plasma lipoproteins in diabetic patients can be decreased by probucol therapy and is not due to glycation. Biochem Pharmacol 43: 995-1000 